\title{
More is not better: the complicated relationship between obesity, critical illness, and infection
}

\author{
Kevin B. Laupland ${ }^{1,2^{*}}$ (i) and Walter Zingg ${ }^{3,4}$
}

(C) 2021 Springer-Verlag GmbH Germany, part of Springer Nature

Obesity is an important determinant influencing the management of patients admitted to intensive care units (ICUs) [1]. Excess body weight is associated with a range of co-morbid chronic conditions, physiologic abnormalities, and immune impairments that challenge the management and increase the risk of complications in critical care. The prevalence of obesity is increasing in many populations worldwide and is influencing the epidemiology of critical care.

In this issue of the journal, Buetti and colleagues pool the results of four previously conducted randomized clinical trials to investigate the risk for intravascular catheter associated infections related to body mass index (BMI) [2]. In their analysis of more than 2000 obese adults, patients admitted to the ICU with $\mathrm{BMI} \geq 40$ were at a twofold increased risk for catheter-related infection as compared to those with BMI 30-39. In addition, obesity was associated with an increased risk for dressing disruption that provides a plausible mechanism accounting at least in part for the observed increase of infection risk.

This analysis is an important addition to the limited body of literature surrounding the risk of intravascular catheter infections in obese patients. The study combines the strength of including a large cohort of patients with data obtained from prospectively conducted clinical trials. It is clinically relevant and quantifies the magnitude of risk of infection as a complication of obesity.

\footnotetext{
*Correspondence: Kevin.laupland@qut.edu.au

${ }^{1}$ Department of Intensive Care Services, Royal Brisbane and Women's Hospital, Level 3 Ned Hanlon Building, Butterfield Street, Brisbane, QLD 4029, Australia

Full author information is available at the end of the article
}

Accordingly, overweight patients should be targeted for interventions aimed at minimizing exposure risk to intravascular catheters [3]. In addition, emphasis on maintenance of dressing integrity in this patient population must be placed [4].

While an important contribution, there are some limitations that merit consideration. As shown in their Fig. 2, the hazards for infection were markedly increased with $\mathrm{BMI} \geq 46$; however, a linear increase in risk associated with increasing BMI at lesser levels was not evident [2]. The authors did not identify any insertion-related variables as significant predictors of infection and this may be due at least in part to limited statistical power as only one of the source studies included detailed information in this regard. In addition, the potential confounding effect of use of ultrasound-guided insertion was not reported. Notably, antiseptic impregnated catheters were not used in this study such that these results may not be generalizable to ICUs that routinely use such devices.

There is an increasing body of literature examining the role of obesity in critical illness [1]. Although management of critically ill obese patients presents many challenges and is associated with increased complications, many studies have found that increasing BMI is "paradoxically" associated with improved survival in ICU [5]. Many explanations have been proposed to explain this phenomenon and include failure to adequately account for confounding variables (such as cancer related weight loss in lower BMI patients), selection bias, and anti-inflammatory immune profile/mediators, endocrine changes and increased energy reserves associated with obesity $[6,7]$. Feeding practices in the ICU may have an important confounding effect as

\section{Springer}


underweight and overweight patients may have relative excess and restriction in caloric intake, respectively, where nutritional prescription is based on ideal body weight-based dosing. Clinical trials examining feeding strategies have tended to show increased risk for infection with higher feeding targets or adjunctive parenteral feeding such that underweight patients may be at increased risk for overfeeding and subsequent complications $[8,9]$.

The study by Buetti et al. adds to the growing body of literature detailing the increased risk for serious complications among very obese individuals following admission to the ICU. Importantly, their study provides a plausible mechanism to explain the increased risk for catheter-related infection associated with obesity. The risk and determinants of other ICU-acquired infections among obese patients admitted to ICU require further investigation and possible mechanisms are shown in Fig. 1. There is a vast body of literature across a wide range of disciplines that consistently attests to the negative health effects resulting from excess body weight. As intensivists we must not be too distracted by the "ICU-obesity survival paradox" as we suspect that this may be a case of missing the "forest for the trees". While it has been a consistent observation that obese patients fair better than normal or underweight patients following admission to ICU, this does not consider the excess risk for obese patients to be admitted to ICU. In other words, obese patients may have an apparent lower case fatality rate in ICU but by virtue of a higher ICU admission incidence risk they may have a similar or even higher population mortality rate as compared to patients with lower BMIs [10]. Reconciling this question is a matter for future investigations. What the study by Buetti et al. demonstrates is that obesity has a negative effect on infection risk and further efforts to reduce the overall burden of obesity associated critical illness are warranted.

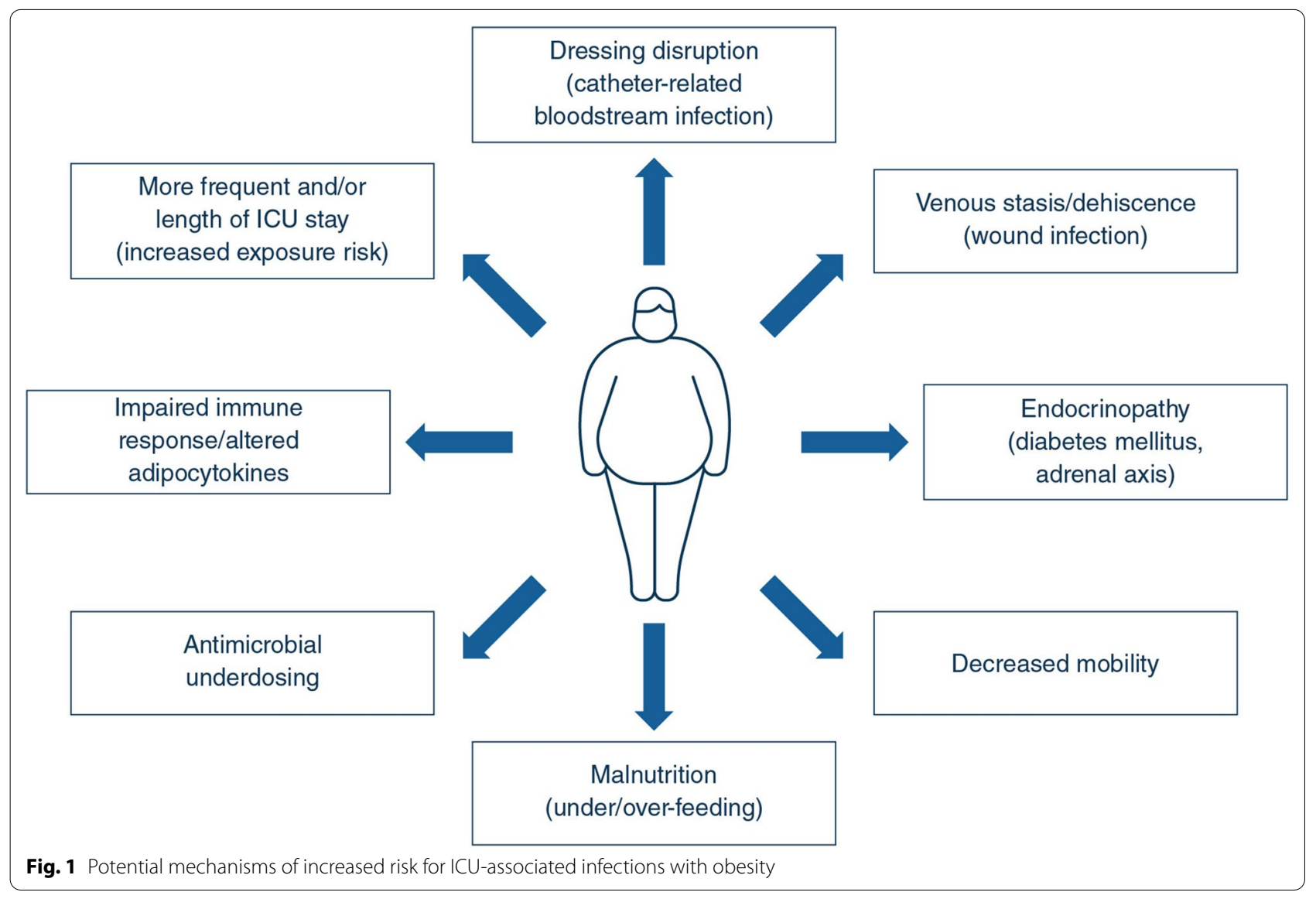




\section{Author details}

${ }^{1}$ Department of Intensive Care Services, Royal Brisbane and Women's Hospital, Level 3 Ned Hanlon Building, Butterfield Street, Brisbane, QLD 4029, Australia.

${ }^{2}$ Queensland University of Technology (QUT), Brisbane, QLD, Australia.

${ }^{3}$ Department of Infectious Diseases and Hospital Epidemiology, University Hospital Zurich, Zurich, Switzerland. ${ }^{4}$ National Institute for Health Research Health Protection Research Unit in Healthcare Associated Infections and Antimicrobial Resistance, Imperial College of London, London, UK.

\section{Declarations}

\section{Conflicts of interest}

The authors have no conflicts of interest to disclose.

\section{Publisher's Note}

Springer Nature remains neutral with regard to jurisdictional claims in published maps and institutional affiliations.

\section{Received: 1 February 2021 Accepted: 15 February 2021}

Published online: 27 February 2021

\section{References}

1. Schetz M, De Jong A, Deane AM, Druml W, Hemelaar P, Pelosi P, Pickers P, Reintam-Blaser A, Roberts J, Sakr Y, Jaber S (2019) Obesity in the critically ill: a narrative review. Intensive Care Med 45:757-769

2. Buetti N, Souweine B, Mermel L, Mimoz O, Ruckly S, Loiodice A, Mongardon N, Lucet JC, Parienti JJ, Timsit JF (2021) Obesity and risk of catheterrelated infections in the ICU. A post hoc analysis of four large randomized controlled trials. Intensive Care Med. https://doi.org/10.1007/s0013 4-020-06336-4

3. Laupland KB, Koulenti D, Schwebel C (2018) The CVC and CRBSI: don't use it and lose it! Intensive Care Med 44:238-240

4. Timsit JF, Bouadma L, Ruckly S, Schwebel C, Garrouste-Orgeas M, Bronchard R, Calvino-Gunther S, Laupland K, Adrie C, Thuong M, Herault MC, Pease S, Arrault X, Lucet JC (2012) Dressing disruption is a major risk factor for catheter-related infections. Crit Care Med 40:1707-1714

5. Zhao Y, Li Z, Yang T, Wang M, Xi X (2018) Is body mass index associated with outcomes of mechanically ventilated adult patients in intensive critical units? A systematic review and meta-analysis. PLoS ONE 13:e0198669

6. Pepper DJ, Demirkale CY, Sun J, Rhee C, Fram D, Eichacker P, Klompas M, Suffredini AF, Kadri SS (2019) Does obesity protect against death in sepsis? A retrospective cohort study of 55,038 adult patients. Crit Care Med 47:643-650

7. Karampela I, Chrysanthopoulou E, Christodoulatos GS, Dalamaga M (2020) Is there an obesity paradox in critical illness? Epidemiologic and metabolic considerations. Curr Obes Rep 9:231-244

8. Heidegger CP, Berger MM, Graf S, Zingg W, Darmon P, Costanza MC, Thibault R, Pichard C (2013) Optimisation of energy provision with supplemental parenteral nutrition in critically ill patients: a randomised controlled clinical trial. Lancet 381:385-393

9. Lambell KJ, Tatucu-Babet OA, Chapple LA, Gantner D, Ridley EJ (2020) Nutrition therapy in critical illness: a review of the literature for clinicians. Crit Care 24:35

10. Laupland KB, Tabah A, Holley AD, Bellapart J, Pilcher DV (2020) Decreasing case-fatality but not mortality rate following admission to intensive care units in Australia, 2005-2018. Chest. https://doi.org/10.1016/j.chest .2020 .11 .059 